\title{
Seasonal Variation of Urban Heat Island and Its Impact on Air-Quality Using SAFAR Observations at Delhi, India
}

\author{
M. Y. Aslam, K. Rama Krishna, G. Beig, M. I. R. Tinmaker, D. M. Chate* \\ Indian Institute of Tropical Meteorology, Pune, India \\ Email: ${ }^{\star}$ chate@tropmet.res.in
}

How to cite this paper: Aslam, M.Y., Krishna, K.R., Beig, G., Tinmaker, M.I.R. and Chate, D.M. (2017) Seasonal Variation of Urban Heat Island and Its Impact on Air-Quality Using SAFAR Observations at Delhi, India. American Journal of Climate Change, 6, 294-305.

https://doi.org/10.4236/ajcc.2017.62015

Received: January 13, 2016

Accepted: May 30, 2017

Published: June 2, 2017

Copyright $\odot 2017$ by authors and Scientific Research Publishing Inc. This work is licensed under the Creative Commons Attribution International License (CC BY 4.0).

http://creativecommons.org/licenses/by/4.0/

(c) (i) Open Access

\begin{abstract}
This paper discussed the urban heat island (UHI) intensity and local air quality by using observational data of project of the System of Air Quality Forecasting and Research (SAFAR) over Delhi during the month of May and December 2013. It is found that UHI magnitudes $\sim 2.2^{\circ} \mathrm{C}$ and $\sim 1.5^{\circ} \mathrm{C}$ are formed at the evening traffic hours during May and December respectively. Also, intensity of $\mathrm{UHI}<0^{\circ} \mathrm{C}$ over daytime is referred as Urban Cool Island (UCI) during May and December. The diurnal $\mathrm{PM}_{2.5}$ concentration shows a bimodal pattern with peaks at morning and evening traffic hours during May and December. The planetary boundary layer height $(\mathrm{PBLH})$ values show higher in magnitude during the daytime and lower in magnitude during the night-time. Whereas, the Ground Heat Flux values are lower during the daytime and higher during the night-time. The wind speed shows lower values during the UHI and higher magnitudes during the UCI formation hours. Concentration of $\mathrm{PM}_{2.5}$ and wind speed shows a strong negative correlation during May $(\mathrm{r}=$ $-0.56, \mathrm{p}=0.002)$ and December $(\mathrm{r}=-0.57, \mathrm{p}=0.001)$ at C V Raman (CVR) site, however, high values in the concentration of $\mathrm{PM}_{2.5}$ during the low wind speed favour the condition for the formation of UCI. The regression analysis indicated that $\mathrm{PM}_{2.5}$ plays a significant role in the daytime cooling and nighttime warming over the urban areas during the low wind speed condition.
\end{abstract}

\section{Keywords}

Urban Heat Island, Ground Heat Flux, Wind Speed, Air Pollution

\section{Introduction}

The urban heat island (UHI) effect is simply defined as the temperature difference between an urban and the surrounding rural regions. This impacts to re- 
lease in additional heat from the urban environment which is a major contribution to the urban heat island [1]. The UHI effect appears more frequently under calm and weak wind conditions with a cloudless sky at night and that its intensity is affected by daytime and nocturnal circulations [2] [3]. Many studies have mentioned that the association between the UHI phenomenon and air pollution with the favourable conditions such as high temperature, low wind speed, low relative-humidity and cloudless, which are important for UHI development, easily triggers air pollution episodes [4] [5].

The basic heat transfer and energy conservation processes, such as conduction, convection and radiation play their characteristic roles in this heat exchange. The structures on ground level, such as walls and roof facets, irrigated gardens, non-irrigated green spaces, lawns and paved areas among others, capture solar radiation to different extents. These natural and man-made structures continuously absorb and store this radiation in the form of heat energy from sunrise till late afternoon. Afterwards, the sun starts setting a side and the environment starts cooling down. The heat energy stored in structures is then released to the environment. The method and quantity of heat released by the urban structures, however, depend on other controllable factors such as the sky view factor and building material. In a typical urban area, massive construction material is placed within a very small space that captures high intensity of solar radiation. The ability of heat release by long-wave radiation in cities is low due to decreased sky view which results in high heat storage in building structures. It is also believed that air pollutants, in particular aerosols that are abundant over polluted urban areas, can absorb and re-radiate long wave radiation and inhibit the corresponding radiative surface cooling producing a pseudo-greenhouse effect, which is responsible for causing UHI [6].

$\mathrm{PM}_{2.5}$, which refers to particulate matter (PM) in air that is less than $2.5 \mu \mathrm{m}$ in aerodynamic diameter, is a key pollutant affecting radiation balance and a main factor in decreasing air quality [7]. Urban landscape features have obvious effects on particulate matter, related closely with $\mathrm{PM}_{2.5}$ concentration [8]. $\mathrm{PM}_{2.5}$ mainly emitted from our daily activities, such as vehicle exhaust, marine aerosols, coal and fuel combustion, burning of agricultural wastes, paved road dust, and secondary sulfates, etc., [9].

Dispersion and transport of lower atmospheric pollutant depend largely on the local planetary boundary layer height (PBLH) structure. Thus, PBLH has been used as a key in weather, climate, and air quality models to determine turbulence mixing, vertical diffusion, convective transport, and atmospheric pollutant deposition [10] [11]. As this is one of the critical physical parameters in atmospheric environmental evaluation, studying PBLH's association with ground level $\mathrm{PM}_{2.5}$ concentration is very important for air pollution and environment quality monitoring.

The UHI has been the focus in many studies [12] [13] [14] [15] while a significant number of these studies document that cities often remain cooler than the countryside from the early morning until the early afternoon during fair 
weather and low wind speed conditions. Some earlier studies qualitatively suggest that the UHI may originate from shadow effects in the urban canyon [16], the daytime energy storage in the urban, attenuate the net radiation due to aerosols [17], or the difference in land cover and the available soil moisture altering the surface energy balance.

\section{Data and Methodology}

\subsection{Observational Datasets}

In this study we mainly focus on the hourly Meteorological data of air temperatures and surface concentrations of $\mathrm{PM}_{2.5}$, collected during the December 2013 and 2015 from the two stations, first Sir C V Raman (CVR) Industrial Training Institute $\left(28.73^{\circ} \mathrm{N}, 77.20^{\circ} \mathrm{E}\right)$, which is located at north from the center of the city. This is completely urbanized area and surrounded majorly with significant infrastructure such as buildings for the residential as well the commercial purposes with a lot of roads and traffic and a little amount of trees and vegetative grass lands as in Figure 1(b). Second the Indian Institute of Tropical Meteorology

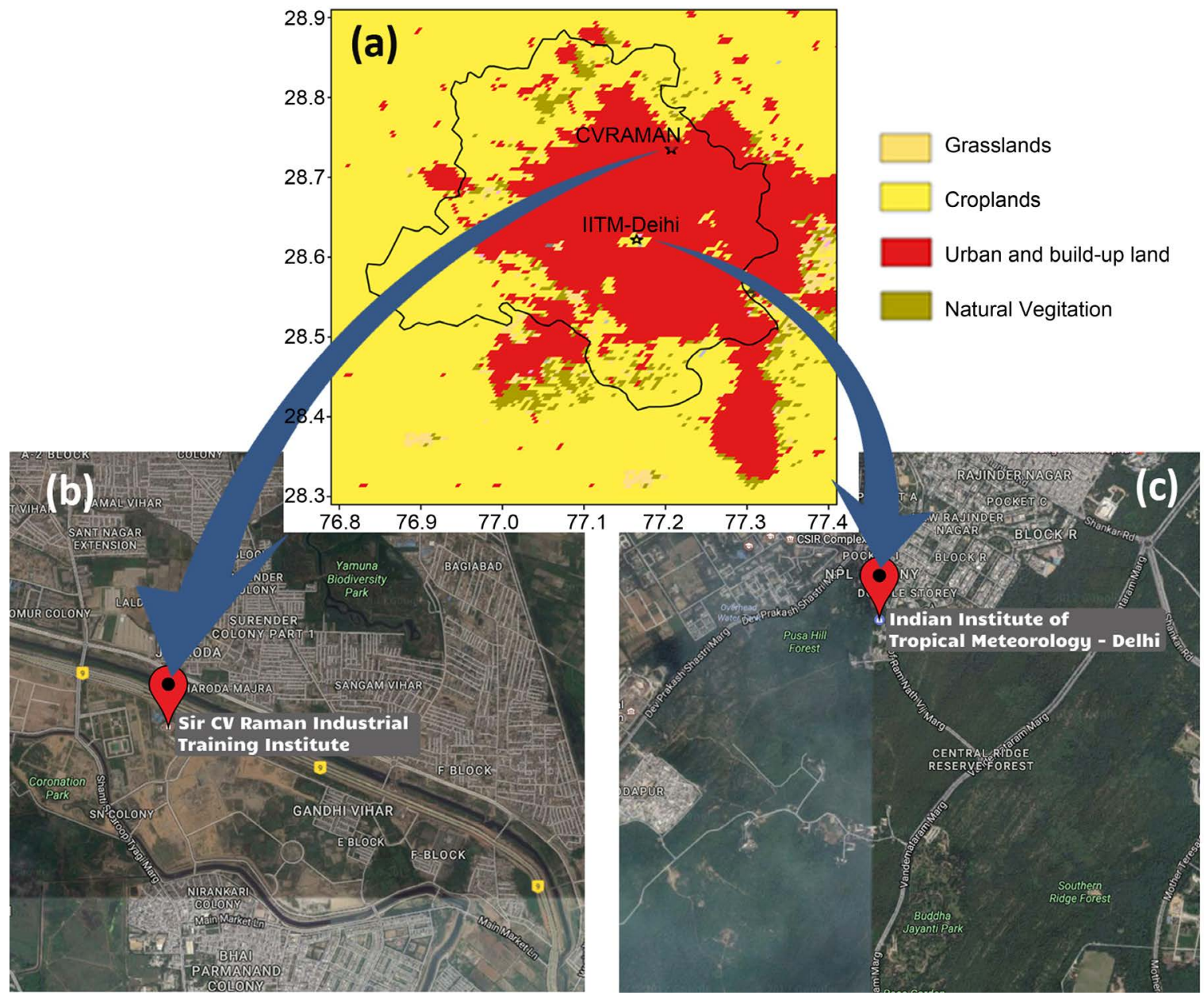

Figure 1. Land use land cover pattern of Delhi and its surroundings, (a) where star mark indicates the station from the SAFAR network and solid line indicated the Delhi boundary, and images from the Google earth for the location of (b) CVR and (c) IITMD and its surroundings. 
(IITMD) Delhi branch $\left(28.64^{\circ} \mathrm{N}, 77.17^{\circ} \mathrm{E}\right)$, which is located at the center of the city. This is majorly surrounded with reserve forest and natural green vegetative grass lands as shown from Figure 1(c). This surface monitoring stations installed and operated at various location of in and around Delhi under the SAFAR (System of Air Quality Forecasting and Research) network. The details of SAFAR network of weather monitoring and air quality monitoring stations setup can be found at http://safar.tropmet.res.in/. The Land Use Land Cover (LULC) classification from Terra/MODIS for the year 2013 for Delhi and its surroundings from Land Processes Distributed Active Archive center (LP DAAP), U.S. Geological survey (USGS) (http://gdex.cr.usgs.gov/gdex/) as shown in Figure 1(a). The UHI intensity is calculated by the simple temperature gradient between the urban areas $\left(T_{u}\right)$ to its surrounding rural areas $\left(T_{r}\right)\left(\right.$ i.e., $T_{U H I}=$ $\left.T_{u}-T_{r}\right)$.

\subsection{Model Datasets}

The Mesoscale model used in this study is the Advanced Research WRF (ARW) model version 3.7. Our model simulation covers the PBLH and ground heat flux for the months of May and December 2013. The simulations were run at a three interactive domains with spatial resolution of $9 \mathrm{~km}, 3 \mathrm{~km}$ and $1 \mathrm{~km}$ which covers part of North India $\left(22^{\circ} \mathrm{N}-34^{\circ} \mathrm{N}-71^{\circ} \mathrm{E}-84^{\circ} \mathrm{E}\right)$, second Domain covers complete Delhi and outer boundaries $\left(25^{\circ} \mathrm{N}-32^{\circ} \mathrm{N}-73^{\circ} \mathrm{E}-80^{\circ} \mathrm{E}\right)$ region and Third domain covers Delhi $\left(27^{\circ} \mathrm{N}-30^{\circ} \mathrm{N}-75^{\circ} \mathrm{E}-78^{\circ} \mathrm{E}\right)$. The vertical grid contained 32 full sigma levels from the surface up to $50-\mathrm{hPa}$. Approximately eight of these levels were below $1 \mathrm{~km}$, thereby providing a fine vertical resolution within the planetary boundary layer. The terrain and land use data for the entire 3 domain were taken from $30 \mathrm{~s}$ data available from the United States Geological Survey (USGS). The National Centre for Environmental Prediction (NCEP) Final Analysis data (FNL) available at 6 hourly intervals on a $1^{\circ} \times 1^{\circ}$ resolution are used as initial and boundary conditions. The model uses two-way nested boundary conditions and they are updated every 6 hours.

The main physics schemes tested and used in the model are microphysics scheme from [18] shortwave radiation scheme from [19] longwave radiation scheme [20] from Rapid Radiative transfer model, Monin-Obukhov surface layer scheme [21], Yonsei University boundary layer scheme and the Noah land surface model. While no cumulus convection scheme is used for the inner domains i.e. $(2 \& 3)$ of the model, the Kain Fritch cumulus convection scheme is applied for the outer domain.

A simulation of the particular intricacies of such an environment is heavily influenced by its depiction of the planetary boundary layer ( $\mathrm{PBL}$ - - that portion of the lower troposphere directly affected by the earth's surface via tropospheresurface exchanges of heat, moisture, and momentum on sub hourly time scales [22] [23]. Exchanges of moisture, heat, and momentum occur within the PBL through mixing associated with turbulent eddies. These eddies influence the way in which lower-tropospheric thermodynamic and kinematic structures evolve. 
Such eddies operate on spatiotemporal scales that cannot be explicitly represented on grid scales and time steps employed in most Mesoscale models. As such, their effects are expressed in these models via the use of PBL parameterization schemes, whose theoretical development is outlined in multiple sources addressing the subject [22] [23] [24], Here we use YSU PBL scheme the main advantage of this scheme is More accurately simulates deeper vertical mixing in buoyancy-driven PBLs with shallower mixing in strong-wind regimes [25].

\section{Results and Discussions}

\subsection{Diurnal Variation of UHI, $\mathrm{PM}_{2.5}$, Ground Heat Flux and Wind Speed during May and December 2013}

From Figure 2 \& Figures 3(a)-(d) are the comparisons of diurnal variability in UHI with $\mathrm{PM}_{2.5}, \mathrm{PBLH}$, Ground heat Flux and wind speed during the months of May and December 2013. Here from Figure 2(a) during the month of May 2013 UHI shows higher in the magnitude from the sunset hour to the sunrise hour in the morning with the peak in the evening around 20:00 hrs with a magnitude of $\sim 2.2^{\circ} \mathrm{C}$. During the daytime from the sunrise to the sunset hours the intensity in UHI shows a peak during the morning traffic hours with intensity below $0^{\circ} \mathrm{C}$ with the formation of Urban Cool Island (UCI). Whereas from Figure 3(a)
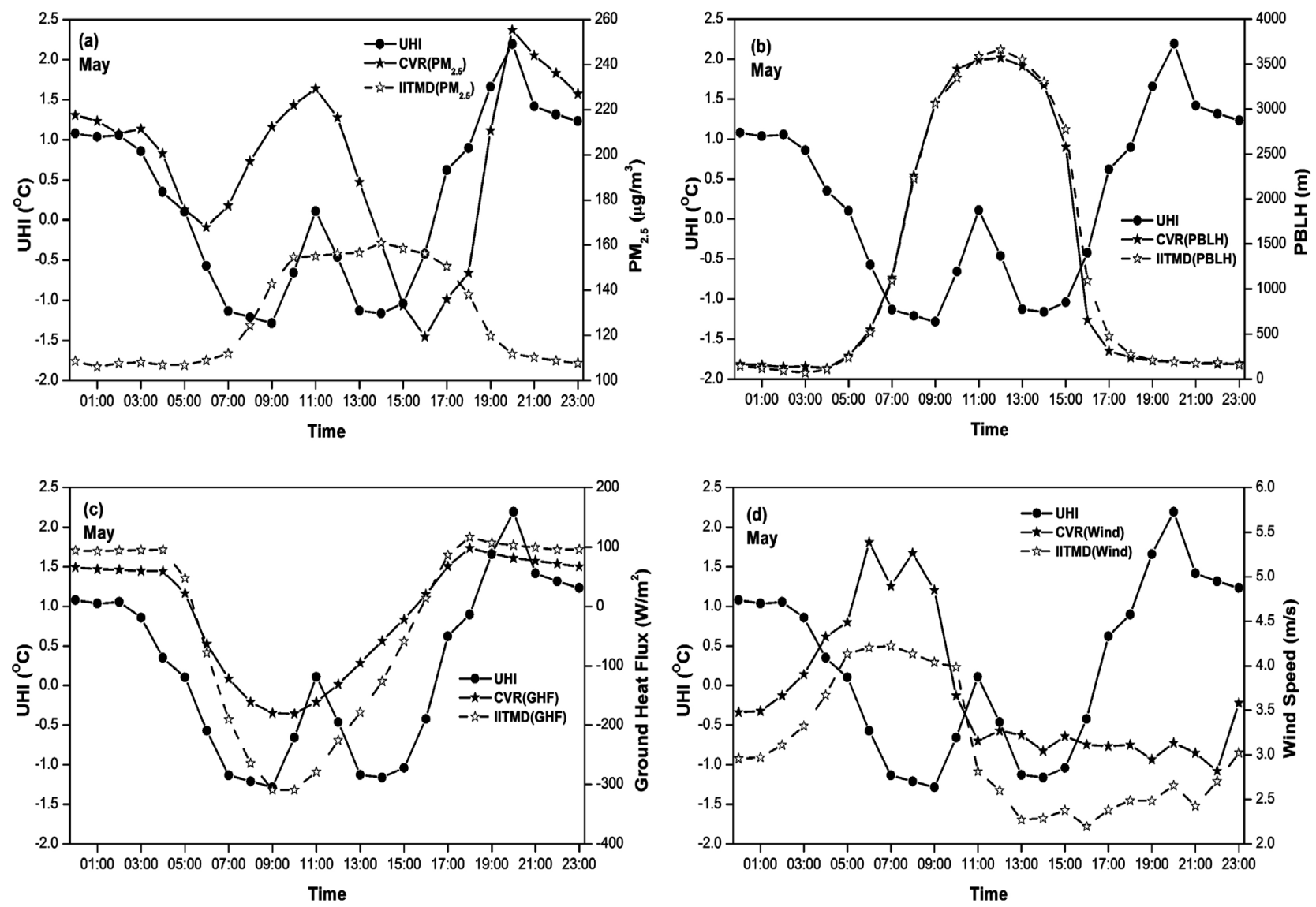

Figure 2. Diurnal cycle of UHI in comparison with the (a) $\mathrm{PM}_{2.5}$ concentration, (b) PBLH, (c) Ground heat flux and (d) Wind speed at CVR and IITMD sites during May 2013. 

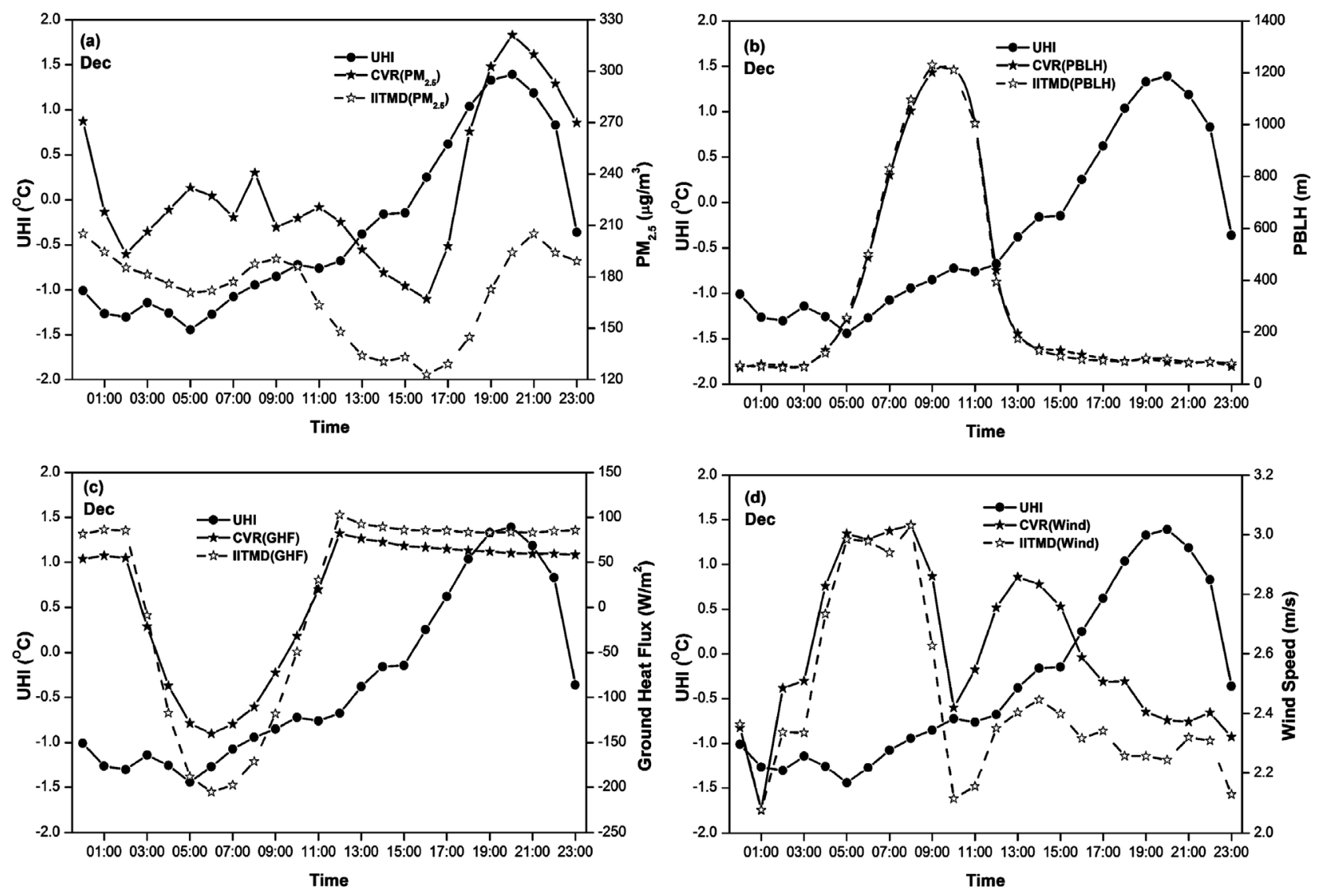

Figure 3. Diurnal cycle of UHI in comparison with the (a) $\mathrm{PM}_{2.5}$ concentration, (b) $\mathrm{PBLH}$, (c) Ground heat flux and (d) Wind speed at CVR and IITMD sites during December 2013.

during the month of December 2013, that UHI intensity shows a peak late in the evening around 20:00 hrs with a magnitude of $\sim 1.5^{\circ} \mathrm{C}$, thereafter it decreases till the sunrise in the morning. During the daytime the magnitude in the intensity of UHI continuously increases with the morning UCI to the night time UHI effect. The $\mathrm{PM}_{2.5}$ concentrations over the CVR site shows a bimodal pattern in both the month May and December with the morning peak around 10:00 hrs and the second peak in the evening peak around 20:00 hrs, the peaks in the $\mathrm{PM}_{2.5}$ concentration hours are related to the morning and evening traffic hours [26]. The peaks in the concentration of $\mathrm{PM}_{2.5}$ during the traffic hours are due to the enhanced anthropogenic activity during the traffic hours [27]. Whereas the concentration of $\mathrm{PM}_{2.5}$ over IITMD site during May 2013 starts increasing after the sunrise hours and peaks around 10:00 hrs and remains almost constant till the evening around 17:00 hrs and then it starts decreasing and remains lower level during the night time as in Figure 2(a) and diurnal variation of $\mathrm{PM}_{2.5}$ concentration at the IITMD location follows the same trend with a lesser in the concentrations compared to the CVR site during December 2013 as in Figure 3(a).

Figure 2(b) and Figure 3(b) show diurnal cycle of UHI and PBLH during the month of May and December 2013. The PBLH is mainly affected by temperature, ground heat flux and wind speed among others [28]. Here the PBLH remain almost at constant height after sunset hours to the sunrise hours and starts 
increasing thereafter and peaks to a maximum during the morning traffic hours and remains constant till the solar insolation is maximum and there after starts decreasing till sunset hours. The PBLH follows the same pattern at the IITMD site with a little lower value at the night time and higher during the day during both months May and December 2013.

Figure 2(c) and Figure 3(c) show the diurnal cycle in the UHI and the Ground heat flux during both months May and December 2013. Here the Ground heat flux value remains higher from sunset to the sunrise hours and starts decreasing there after the sunrise hour and attains a least value during 09:00 hrs and there after it starts increasing and attains a maximum during 17:00 hrs in May month and in December month it attains the least values around 06:00 hrs and there after it starts increasing and attains a maximum during 11:00 hrs. Whereas at the IITMD site the ground heat flux values follows the same trend as CVR site values with lesser in magnitude in the morning hours and a little slight higher in magnitude during the night hours during both the months May and December 2013. The strong decrease in the ground heat flux values between the nighttime and daytime suggest that more thermal energy absorption by the urban surfaces [29].

The diurnal variation in the wind speed during May and December 2013 over the CVR and IITMD sites are seen in Figure 2(d) and Figure 3(d). Here the wind speed shows peaks during 06:00 hrs and 08:00hrs after the sunrise and then start decreasing and attains a least values and remain constant from 13:00 hrs to 22:00 hrs in the mid-night during May 2013 as in Figure 2(d). But the wind speed shows a peak during 08:00 hrs in the morning and 15:00 hrs in the evening, whereas during the night hours the winds are low as compares to that of the morning hours. The winds are lower in the magnitude during the same evening traffic hours when the UHI intensity is higher around 20:00 hrs during December 2013 as in Figure 3(d). The wind speed at the IITMD site follows the same trend with a lesser in the magnitude during both months May and December 2013. Changes in the concentration of $\mathrm{PM}_{2.5}, \mathrm{PBLH}$ and Ground heat flux are mainly caused due to the changes in the magnitude of the wind speed [30].

The UHI formation during the evening traffic hours is due to increase in the concentration of $\mathrm{PM}_{2.5}$ with decrease in the height of the PBLH and higher in the magnitude of the ground heat flux and lower wind speed. Before sunrise the concentration in the $\mathrm{PM}_{2.5}$ are lower in the magnitude and with the decrease in the PBLH and lower in the ground heat flux values and lower in the wind speed, which leads to the formation of the Urban Cool Island (UCI).

\subsection{Regression Analysis of UHI}

Figures 4(a)-(d) show regression analysis to explore the correlation between the UHI and its two possible dependent variables during May 2013. The first variable is the concentration of $\mathrm{PM}_{2.5}$, here Figure 4(a) shows the correlation of UHI with the first variable exists a strong positive correlation at both CVR $(\mathrm{r}=$ 

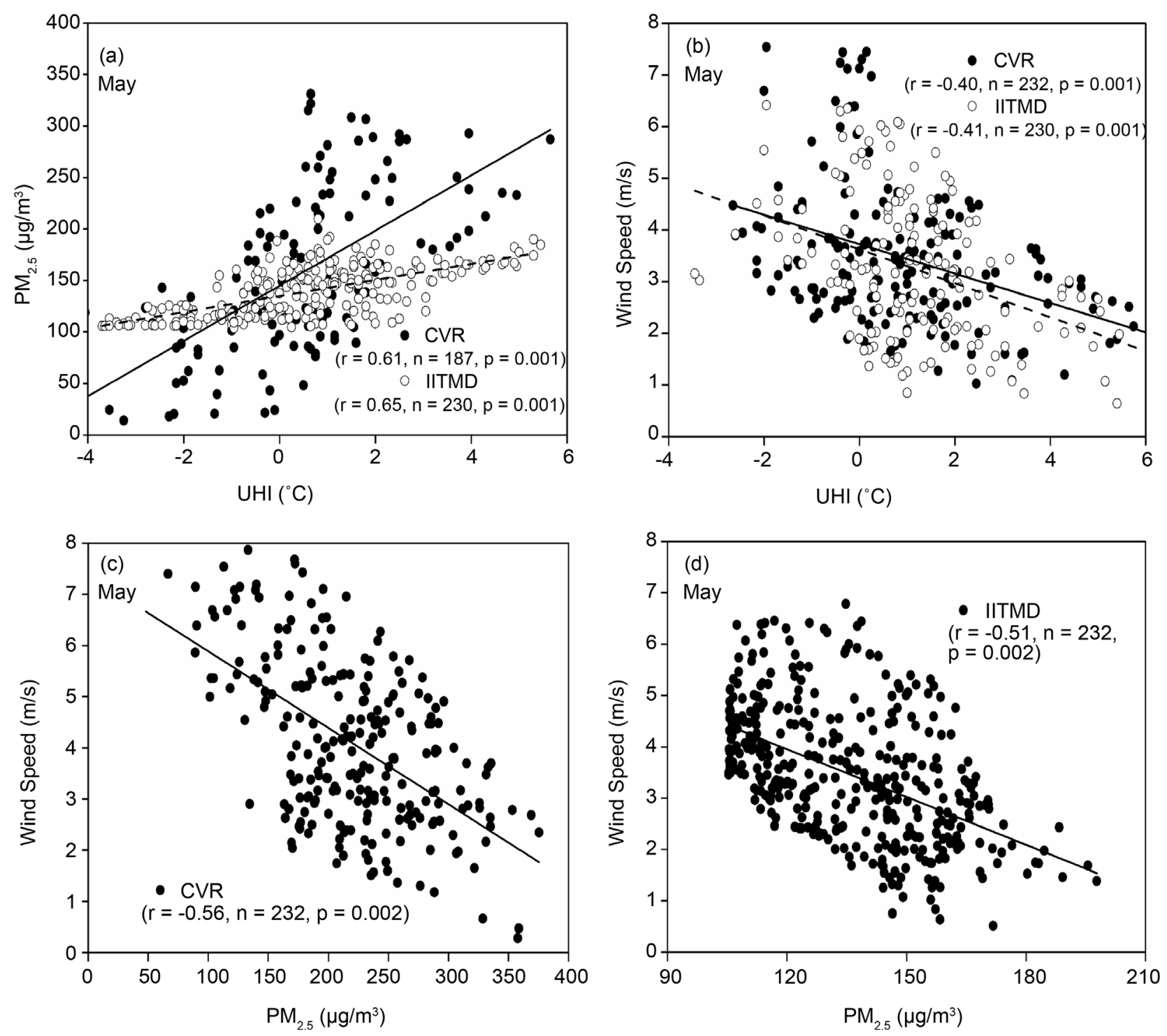

Figure 4. Linear regression of the UHI with the (a) $\mathrm{PM}_{2.5}$ concentration and (b) Wind speed, and regression between the $\mathrm{PM}_{2.5}$ concentration and Wind speed during at (c) CVR and (d) IITMD during May 2013.

$0.61, \mathrm{p}=0.001)$ and IITMD $(\mathrm{r}=0.65, \mathrm{p}=0.001)$ sites. The second variable is the wind speed, from Figure $4(\mathrm{~b})$ shows a negative correlation of UHI with the second variable both at the CVR $(r=-0.40, \mathrm{p}=0.001)$ and IITMD $(\mathrm{r}=-0.41, \mathrm{p}=$ 0.001 ) site respectively. From Figure $4(c)$ and Figure $4(d)$ show the correlation between the two dependent variables concentration of $\mathrm{PM}_{2.5}$ and wind speed shows a strong negative correlation at both the sites CVR $(r=-0.56, p=0.002)$ and $\operatorname{IITMD}(\mathrm{r}=-0.51, \mathrm{p}=0.002)$.

Figures 5(a)-(d) show the regression analysis to explore the correlation between the UHI and its two possible dependent variables during December 2015. The first variable is the concentration of $\mathrm{PM}_{2.5}$, here Figure 5(a) shows that the correlation of UHI with the first variable is positive at both CVR $(r=0.62, p=$ $0.001)$ and IITMD $(r=0.40, p=0.003)$ sites. The second variable, wind speed from Figure $5(\mathrm{~b})$ shows a negative correlation of UHI at the CVR $(r=-0.40, p=$ 

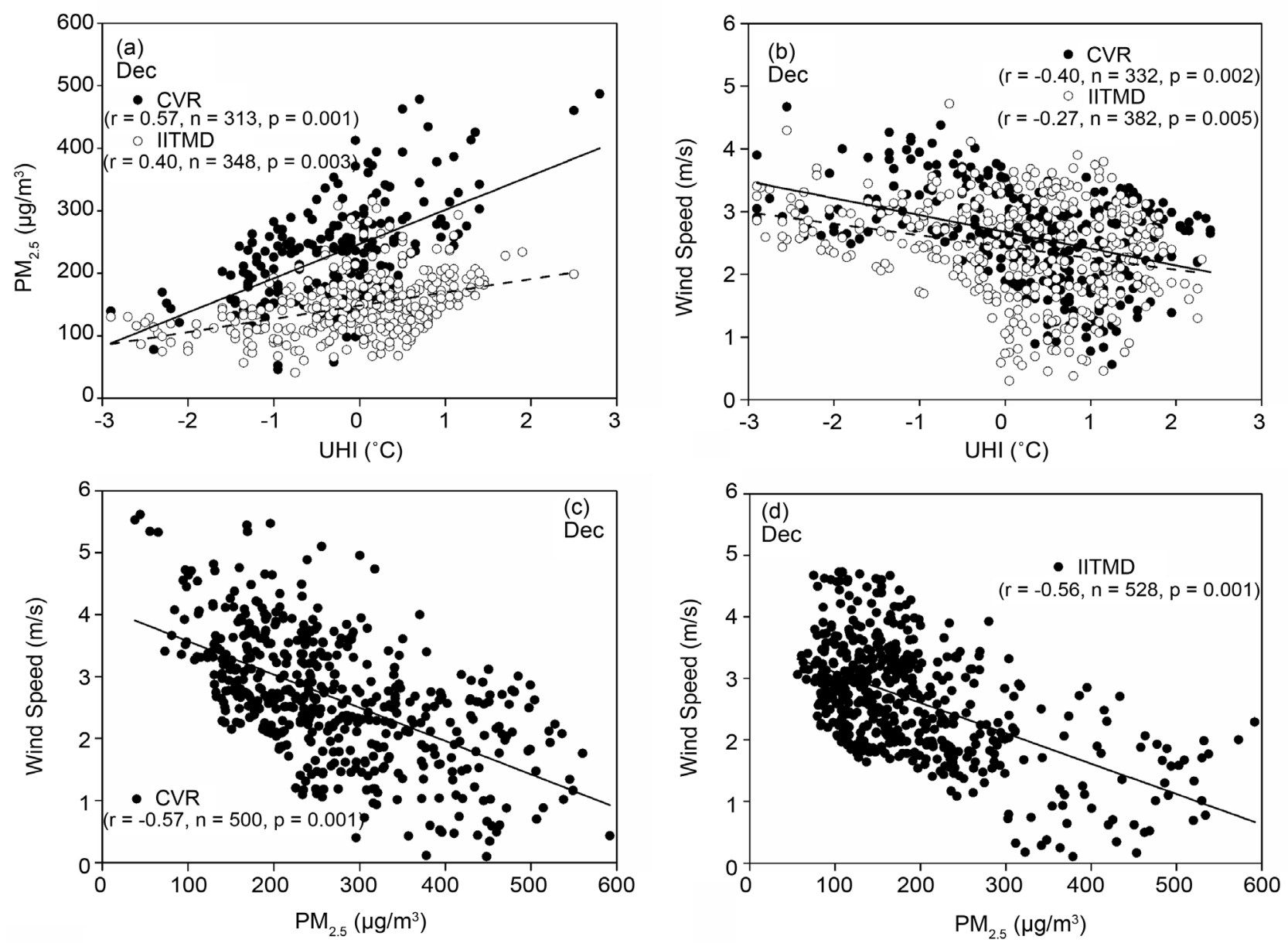

Figure 5. Linear regression of the UHI with the (a) $\mathrm{PM}_{2.5}$ concentration and (b) Wind speed, and regression between the $\mathrm{PM}_{2.5}$ concentration and Wind speed during at (c) CVR and (d) IITMD during December 2013.

$0.002)$ and $\operatorname{IITMD}(\mathrm{r}=-0.27, \mathrm{p}=0.005)$ site respectively. From Figure $5(\mathrm{c})$ and Figure 5(d) show the correlation between the two dependent variables concentration of $\mathrm{PM}_{2.5}$ and wind speed, it shows a strong negative correlation at both the sites CVR ( $\mathrm{r}=-0.57, \mathrm{p}=0.001)$ and IITMD $(\mathrm{r}=-0.56, \mathrm{p}=0.001)$.

The formation of UHI is mainly favoured with the low wind speed and high concentration of $\mathrm{PM}_{2.5}$ with a positive correlation between the UHI and $\mathrm{PM}_{2.5}$ concentrations. Whereas, a negative correlation between the wind speed and concentrations of $\mathrm{PM}_{2.5}$ [31] during both May and December. The results from the correlation analysis in the present study suggest "Urban Cool Island" formation over Delhi during daytime in the months of May and December under low wind conditions. Thus it is found that during the daytime the extinction of incoming solar radiation by the aerosols are more dominating than the absorption of outgoing long wave radiation. Thus results suggest the daytime negative forcing by the aerosols during May and December under low wind speed and clear sky conditions [32] [33].

\section{Conclusions}

We performed analysis of site-specific air quality and weather data from the 
project SAFAR over Delhi during May and December 2013. UHI of $\sim 2.2^{\circ} \mathrm{C}$ and $\sim 0.5^{\circ} \mathrm{C}$ observed over nighttime with a peak around 20:00 hrs during May and December respectively. The $\mathrm{PM}_{2.5}$ concentration shows a bimodal pattern with first peak at 10:00 hrs and the second peak at 20:00 hrs. The peaks in the diurnal concentration of $\mathrm{PM}_{2.5}$ correspond to morning and evening traffic hours during May and December. The evening peak in the concentration of $\mathrm{PM}_{2.5}$, ground heat flux values, low PBLH and wind speed leads to the formation of UHI. On the other hand, during daytime, peak in the concentration of $\mathrm{PM}_{2.5}$ during the morning traffic hours, high PBLH, low intensity of Ground heat flux and less wind speed leads to a peak in the intensity of $\mathrm{UHI}<0^{\circ} \mathrm{C}$ leading to the formation of UCI during May and December.

During May and December, the concentration of $\mathrm{PM}_{2.5}$ shows a positive correlation with UHI intensity at CVR site $(r=0.61, p=0.001 ; \mathrm{r}=0.57, \mathrm{p}=0.001)$, and IITMD site $(r=0.65, p=0.0011 ; r=0.40, p=0.003)$ and negative correlation of wind speed correlation with UHI intensity at the CVR $(r=-0.40, p=0.001$; $\mathrm{r}=-0.40, \mathrm{p}=0.002)$ and $\operatorname{IITMD}(\mathrm{r}=-0.41, \mathrm{p}=0.001 ; \mathrm{r}=-0.27, \mathrm{p}=0.005)$. Also, concentration of $\mathrm{PM}_{2.5}$ and wind speed shows a strong negative correlation at CVR $(\mathrm{r}=-0.56, \mathrm{p}=0.002 ; \mathrm{r}=-0.57, \mathrm{p}=0.001)$ and IITMD $(\mathrm{r}=-0.51, \mathrm{p}=$ $0.002 ; \mathrm{r}=-0.56, \mathrm{p}=0.001$ ). The results from the regression analysis of wind speed and $\mathrm{PM}_{2.5}$ indicated the significant role played by the $\mathrm{PM}_{2.5}$ levels in the daytime cooling and nighttime warming over the urban areas which moderated the diurnal UHI during the low wind speed condition.

\section{Acknowledgements}

The authors are thankful to Director, IITM for his constant support and encouragement. The authors are all thankful to Ministry of Earth Science for providing funds for SAFAR network. The authors also wish to thank SAFAR team who helped in the collection of data.

\section{References}

[1] Taha, H. (1997) Urban Climates and Heat Islands: Albedo, Evapotranspiration, and Anthropogenic heat. Energy and Buildings, 25, 99-103.

[2] Kim, Y.H. and Baik, J.J. (2004) Daily Maximum Urban Heat Island Intensity in Large Cities of Korea. Theoretical and Applied Climatology, 79, 151-164. https://doi.org/10.1007/s00704-004-0070-7

[3] Lam, K., et al. (2005) Study on an Ozone Episode in Hot Season in Hong Kong and Transboundary Air Pollution over Pearl River Delta Region of China. Atmospheric Environment, 39, 1967-1977.

[4] Weng, Q. and Yang, S. (2004) Managing the Adverse Thermal Effects of Urban Development in a Densely Populated Chinese City. Journal of Environmental Management, 70, 145-156.

[5] Zhao, S., et al. (2006) Ecological Consequences of Rapid Urban Expansion: Shanghai, China. Frontiers in Ecology and the Environment, 4, 341-346. https://doi.org/10.1890/1540-9295(2006)004[0341:ECORUE]2.0.CO;2

[6] Memon, R.A., Leung, D.Y.C. and Chunho, L.I.U. (2008) A Review on the Genera- 
tion, Determination and Mitigation of Urban Heat Island. Journal of Environmental Sciences, 20, 120-128.

[7] Yang, S.U.N. and Yuesi, W. (2010) At Beijing and Tianjin from Towers during Summer and Autumn 2006. Advances in Atmospheric Sciences, 27, 123-136.

[8] Wu, J., et al. (2015) Effects of Urban Landscape Pattern on $\mathrm{PM}_{2.5}$ Pollution: A Beijing Case Study. PLoS ONE, 10, e0142449. https://doi.org/10.1371/journal.pone.0142449

[9] Pui, D.Y.H., Chen, S.C. and Zuo, Z. (2014) $\mathrm{PM}_{2.5}$ in China: Measurements, Sources, Visibility and Health Effects, and Mitigation. Particuology, 13, 1-26.

[10] Stevens, B. (2002) Entrainment in Stratocumulus-Topped Mixed Layers. Quarterly Journal of the Royal Meteorological Society, 128, 2663-2690. https://doi.org/10.1256/qj.01.202

[11] Konor, C.S., et al. (2009) Parameterization of PBL Processes in an Atmospheric General Circulation Model: Description and Preliminary Assessment. Monthly Weather Review, 137, 1061-1082. https://doi.org/10.1175/2008MWR2464.1

[12] Deosthali, V. (2000) Impact of Rapid Urban Growth on Heat and Moisture Islands in Pune City, India. Atmospheric Environment, 34, 2745-2754.

[13] Oke, T.R. (1981) Canyon Geometry and the Nocturnal Urban Heat Island: Comparison of Scale Model and Field Observations. Journal of Climatology, 1, 237-254. https://doi.org/10.1002/joc.3370010304

[14] Pandey, A.K., et al. (2014) Spatio-Temporal Variations of Urban Heat Island over Delhi. Urban Climate, 10, 119-133.

[15] Mohan, M. (2012) Urban Heat Island Assessment for a Tropical Urban Airshed in India. Atmospheric and Climate Sciences, 2, 127-138. https://doi.org/10.4236/acs.2012.22014

[16] Steeneveld, G.J., et al. (2011) Quantifying Urban Heat Island Effects and Human Comfort for Cities of Variable Size and Urban Morphology in the Netherlands. Journal of Geophysical Research Atmospheres, 116, 1-14. https://doi.org/10.1029/2011jd015988

[17] Rotach, M.W., et al. (2005) BUBBLE-An Urban Boundary Layer Meteorology Project. Theoretical and Applied Climatology, 81, 231-261. https://doi.org/10.1007/s00704-004-0117-9

[18] Lin, Y.-L., Farley, R.D. and Orville, H.D. (1983) Bulk Parameterization of the Snow Field in a Cloud Model. Journal of Climate and Applied Meteorology, 22, 1065 1092. https://doi.org/10.1175/1520-0450(1983)022<1065:BPOTSF $>2.0 . C O ; 2$

[19] Dudhia, J. (1989) Numerical Study of Convection Observed during the Winter Monsoon Experiment Using a Mesoscale Two-Dimensional Model. Journal of the Atmospheric Sciences, 46, 3077-3107. https://doi.org/10.1175/1520-0469(1989)046<3077:NSOCOD>2.0.CO;2

[20] Mlawer, E.J., et al. (1997) Radiative Transfer for Inhomogeneous Atmospheres: RRTM, a Validated Correlated-k Model for the Longwave. Journal of Geophysical Research, 102, 16663. https://doi.org/10.1029/97JD00237

[21] Monin, A.S. and Obukhov, A.M. (1954) Basic Laws of Turbulent Mixing in the Surface Layer of the Atmosphere. Contrib. Geophys. Inst. Acad. Sci. USSR, 24, 163-187.

[22] Stull, R.B. (1988) An Introduction to Boundary Layer Meteorology. Kluwer Academic, Berlin/Heidelberg, 666 p. https://doi.org/10.1007/978-94-009-3027-8

[23] Stensrud, D. (2007) Parameterization Schemes: Keys to Understanding Numerical Weather Prediction Models. Cambridge University Press, Cambridge, UK. https://doi.org/10.1017/cbo9780511812590 
[24] Holton, J.R. (2004) Introduction to Dynamic Meteorology. 4th Edition, Elsevier, Amsterdam, $535 \mathrm{p}$.

[25] Hong, S. and Lim, J. (2006) The WRF Single-Moment 6-Class Microphysics Scheme (WSM6). Journal of the Korean Meteorological Society, 42, 129-151.

[26] De Gaetano, A. (2004) Temporal, Spatial and Meteorological Variations in Hourly $\mathrm{PM}_{2.5}$ Concentration Extremes in New York City. Atmospheric Environment, 38, 1547-1558. https://doi.org/10.1016/j.atmosenv.2003.12.020

[27] Zhao, X., et al. (2009) Seasonal and Diurnal Variations of Ambient $\mathrm{PM}_{2.5}$ Concentration in Urban and Rural Environments in Beijing. Atmospheric Environment, 43, 2893-2900. https://doi.org/10.1016/j.atmosenv.2009.03.009

[28] Liu, S. and Liang, X.Z. (2010) Observed Diurnal Cycle Climatology of Planetary Boundary Layer Height. Journal of Climate, 23, 5790-5809. https://doi.org/10.1175/2010JCLI3552.1

[29] Cui, Y.Y. and De Foy, B. (2012) Seasonal Variations of the Urban Heat Island at the Surface and the Near-Surface and Reductions due to Urban Vegetation in Mexico City. Journal of Applied Meteorology and Climatology, 51, 855-868. https://doi.org/10.1175/JAMC-D-11-0104.1

[30] Gao, M., et al. (2015) Modeling Study of the 2010 Regional Haze Event in the North China Plain. Atmospheric Chemistry and Physics Discussions, 15, 22781-22822. https://doi.org/10.5194/acpd-15-22781-2015

[31] Pandey, P., et al. (2012) A Study of Urban Heat Island and Its Association with Particulate Matter during Winter Months over Delhi. Science of the Total Environment, 414, 494-507.

[32] Ramanathan, V., Chung, C., Kim, D., Bettge, T., Buja, L., Kiehl, J.T., Washington, W.M., Fu, Q., Sikka, D.R. and Wild, M. (2005) Atmospheric Brown Clouds: Impacts on South Asian Climate and Hydrological Cycle. Proceedings of the National Academy of Sciences of the United States of America, 102, 5326-5333. https://doi.org/10.1073/pnas.0500656102

[33] Singh, S., Nath, S., Kohil, R. and Singh, R. (2005) Aerosols over Delhi during PreMonsoon Months: Characteristics and Effects on Surface Radiation Forcing. Geophysical Research Letters, L13808. https://doi.org/10.1029/2005gl023062

\section{Scientific Research Publishing}

Submit or recommend next manuscript to SCIRP and we will provide best service for you:

Accepting pre-submission inquiries through Email, Facebook, LinkedIn, Twitter, etc. A wide selection of journals (inclusive of 9 subjects, more than 200 journals)

Providing 24-hour high-quality service

User-friendly online submission system

Fair and swift peer-review system

Efficient typesetting and proofreading procedure

Display of the result of downloads and visits, as well as the number of cited articles

Maximum dissemination of your research work

Submit your manuscript at: http://papersubmission.scirp.org/

Or contact ajcc@scirp.org 